\title{
CONJUNTOS RESIDENCIALES AL MARGEN DEL PLANEAMIENTO EN LA PERIFERIA DE ZARAGOZA
}

\author{
José SANCHO MARTI
}

\begin{abstract}
RESUMEN: Se plantea la problemática en torno“a las "parcelaciones clandestinas" en los alrededores de Zaragoza, con un analisis de los factores que han intervenido en el proceso y su distribución espacial. El elevado número de usuarios exige buscar soluciones alternativas y cauces de legalización.
\end{abstract}

\begin{abstract}
The question about "clandestine plotting" location in Zaragoza's surroundings, is raised. An analysis of the factors which have taken part in this process and its spatial distribution is made. The high number of users demands alternative solutions and legalization channels.
\end{abstract}

La problemática en torno a las parcelaciones clandestinas con expectativas de segunda residencia, aparecidas al margen de toda disciplina urbanística, y las especiales circunstancias que las han potenciado, ha dado lugar a un fenómeno, que, además de infringir la Ley del Suelo, se ha extendido de forma alarmante y plantea serios conflictos a los Ayuntamientos y a la D.G.A.

Es preocupante, además, porque está siendo acaparado por clases sociales medias y bajas, preferentemente, con una actitud reivindicativa ante su derecho a vivir en "plena naturaleza" y puede ser el germen de futuros conflictos sociales y agravios comparativos injustificables, al pretender utilizar un suelo, como soporte de edificación, sin dotaciones ni cobertura legal, a precio muy reducido y prescindiendo de todo formalismo administrativo.

Esta forma de actuar, a parte de la desorganización del territorio, puede degenerar en actitudes viciosas difíciles de cortar cuando arraigan y poco rentables electoralmente, si se imponen medidas correctoras para desterrar un problema que afecta:

de manera individual , a gran número de ciudadanos, que por desinformación o mala fe, se introducen insensiblemente en un mundo de incertidumbres e inseguridades.

Socialmente, por lo que representa de destrucción irreversible de recursos ecológicos y paisajísticos, que a todos nos pertenecen.

Económicamente, por la detracción de fuentes agrícolas de producción, sin fijarse en la potencialidad rentable del suelo.

Institucionalmente, porque existe el riesgo de perder la credibilidad democrática, si no se proyecta la imagen de garantizar el imperio de la Ley.

Estructuralmente, por lo que supone de desarticulación del territorio, dando estructuras dispersas y desordenadas. 


\section{EVOLUCION}

En Zaragoza y su entorno este fenómeno, que en la actualidad representa 171 actuaciones y 7.021 parcelas trazadas, inicia su andadura de forma vacilante a principios de la década de los sesenta y alcanza su primer techo en 1970, para descender más tarde, ante los primeros avisos de la crisis (1972-73). Pero precisamente cuando ésta se reafirma, adquiere su mayor expansión y en el bienio 1978-79 surgen 53 promociones, con una oferta de 2.559 parcelas, sobre una superdicie de 586'5 Has. Su caída posterior, a partir de 1984-85, también ha sido expectacular, aunque en ello han intervenido factores extraños a su propia dinámica (mayor vigilancia, amenaza de demoliciones, sanciones, etc.).

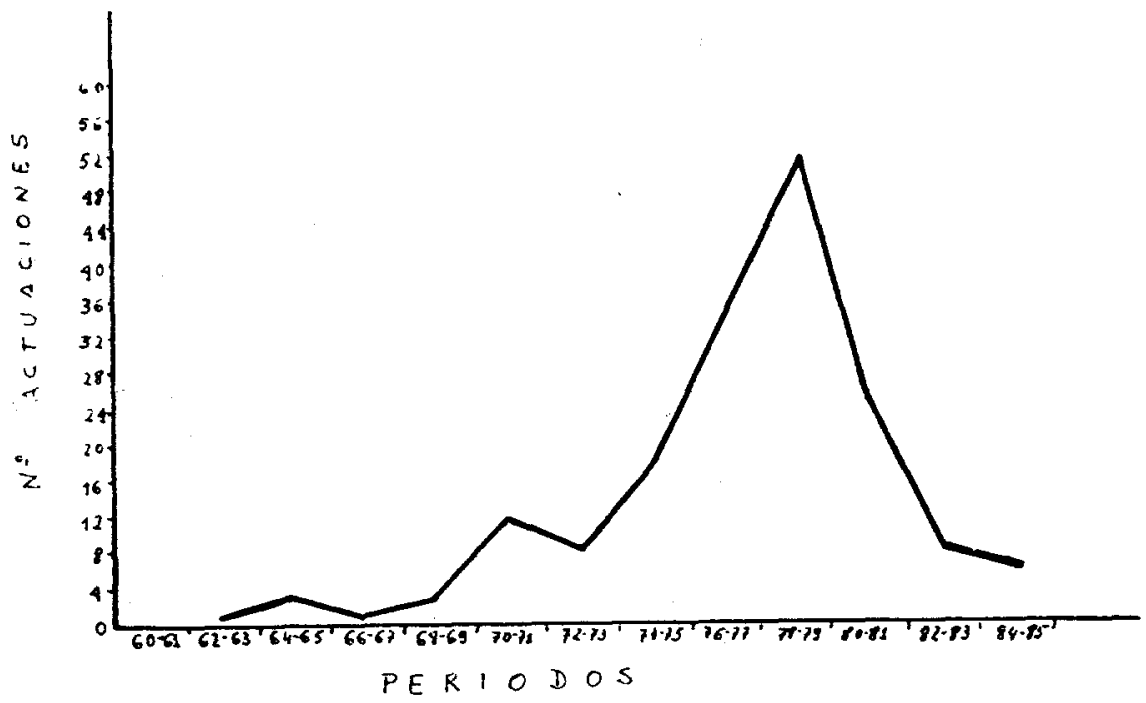

Por eso, en una primera aproximación puede afirmarse que nos hallamos ante un fenómeno fugaz (que ha dejado como secuela, más de 5.000 viviendas, mejor o peor dotadas) y un fenómeno postcrisis. Incluso puede interpretarse como producto de la crisis, pues alcanza las cotas más altas, precisamente en los momentos más inciertos y cuando ésta muestra las consecuencias más serias (paro, economía sumergida, desempleo...), que afectan, de manera especial, a las capas más bajas de la escala social, atraidas por la posibilidad de invertir en un bien estable y seguro como es la tierra, con el que resuelven a su vez la eventualidad de la propia subsistencia o la devaluación de sus ahorros ante la galopante inflacción.

Los factores que han desencadenado este proceso, son muy variados:

a) de origen administrativo o político, al no detenerse el problema en sus inicios, por una normativa poco clara o por benevolente permisividad por parte de las autoridades locales.

b) de orden social, pueden citarse entro otros: la reducción de la semana laboral y el pasado campesino de gran parte de nuestro proletariado industrial, que tiene al "contacto con la 
naturaleza", como un ocio liberador, al que se acogen también gran número de jubilados, pensionistas y parados.

c) Poder contar con un medio favorable, que ofrece cursos de agua, un copioso acuífero y desnivelaciones topográficas, que en el caso de las muelas o graderías de terrazas, proporcionan espléndidas panorámicas y representan un revulsivo ante los agobiantes calores del verano y persistentes nieblas en invierno, características del microclima urbano de Zaragoza.

d) Desde un punto de vista económico , el suelo rústico es muchísimo más barato que el urbano con todas sus dotaciones. Coincide además con un incremento de la renta disponible por parte de la población laboral, que le permite orientar sus ahorros hacia el ocio y el descanso (propios de la parcela de fin de semana), tras haber satisfecho la necesidad de primera vivienda. El suelo, además de barato, se ofrece con grandes facilidades de pago, porque el promotor oferta un producto en el que la inversión, para su puesta en valor, es realmente baja, pues lejos del modelo tradicional en el que este valor lo daban las dotaciones, ahora se ofrece accesibilidad, vistas, naturaleza, paz... que no tienen una cuantificación económica directa.

e) Existen factores estructurales, como la red de caminos, fragmentación de grandes fincas por repartor hereditarios o las nuevas tecnologías, que permiten suplir muchas carencias.

f) El componente ideológico es muy digno de tenerse en cuanta, pues en la adquisición de una parcela, hay mucho de "logro social" y satisfacción pequeño-burguesa por la posesión de la tierra; unido todo ello a la exaltación de la naturaleza por una propaganda que destaca su poder evocador y fomenta esa "ideología clorofila" que choca con el contexto hostil en el que se desenvuelve la ciudad (ruidos, polución, aislamiento, controles...).

g) Hay un hecho coyuntural , que puede explicar también el incremento de este proceso: el "vacío de poder municipal" antes de las elecciones democráticas de 1979, o incluso, como señala M. Herce (Murcia, 1984) porque tras ellas, la reacción de algunos municipios fue tardía "quizás inhibidos por afinidades ideológicas o de clase con los implicados".

h) Entre los Factores legales y urbanísticos, se halla la poca claridad en las disposiciones, con resquicios en los que apoyarse los infractores, que de forma interesada pudieron acogerse al art. 69.1 de la Ley del Suelo de 1956, en el que se permite la edificación de $1 \mathrm{~m}^{3} / 5 \mathrm{~m}^{2}$, de forma homogénea en todo el suelo rústico. Estas posibilidades quiere resolverlas la Ley de Reforma de la Ley del Suelo de 1975 en su art. 86 y la Ley de Reforma y Desarrollo Agrario de 1973, cuando establece en su art. 44.1 la necesidad de respetar las unidades mínimas de cultivo. Sin embargo es precisamente esa Ley la que sirve de apoyo a los promotores en sus arts. 43.1, 44.2, 44.3 y 47.1, al permitir "segregar civilmente fincas rústicas destinadas al uso agrícola", para autoconsumo familiar, incluso por debajo de la unidad mínima de cultivo.

Así aparece el famoso "Huerto Familiar ", eufemismo que encubre a la parcela, y el refugio de utillage agrícola, al chalet o casa de campo. El concepto de "núcleo de población", según el art. 94.1 de la L.R.S. se presta a muchas confusiones y depende del criterio de los distintos entes autonómicos.

Como vemos, son numerosas las razones que han influido en este fenómeno, realmente complejo y caracterizado:

Espacialmente, por su atomización y dispersión; lo que dificulta su normalización, pues salvando algunas excepciones, es tan reducido el número de usuarios por parcelación, que los costes por dotación de servicios urbanísticos imprescindibles, serían inviables económicamente. 
En cuanto al proceso de promoción, por haberse desenvuelto con gran anarquía, sin cobertura de planeamiento y manejado por profanos, con más audacia que capital y organización.

Respecto al parcelista, porque pretendiendo satisfacer su aspiración de casa de campo, con poco dinero, adquiere suelo no urbanizable, sin planeamiento parcial, sin proyecto técnico, sin licencias ni tasas... a cambio de tener que burlar a la Administración, para no ser víctima de soluciones contundentes; adquirir un terreno, y construir en él, sin saber si podrá escriturarlo; sufrir incomodidades por falta de dotaciones y sobre todo, la frustración e insatisfacción que produce; adquirir "ocio" y en su lugar, encontrar trabajo; buscar naturaleza y libertad, que truncan los coches y el vecindario; comprar pensando en los hijos, que como se aburren, no quieren ir.

Si se analizan los niveles o grados de urbanización, se observa que la casi totalidad de parcelaciones clandestinas, se proyectan sin la más mínima infraestructura, a no ser el acceso rodado o la eventual proximidad de tendido eléctrico en condiciones precarias.

Atendiendo al tipo de construcción, la heterogeneidad es la tónica, pero con una muestra variadísima, en la que predomina la solidez sobre el gusto en el diseño y la autoconstrucción, sobre el proyecto técnico, que contrasta con algún lujoso chalet.

Sobre la morfología parcelaria, predomina la irragularidad, con todo tipo de trazados (ortogonales, envolventes, fondos de saco,...) y la estrechez de viales, pretendiendo aprovechar al máximo el espacio.

La amalgama de situaciones descrita, tiene múltiples repercusiones:

a) En el plano urbanístico, además de la aparición de importantes núcleos de infravivienda, su origen al margen de un planeamiento razonable, representa un pie forzado para futuros planes, plantea problemas de seguridad (contaminación de acuíferos, inundaciones, incendios...) y resta autoridad moral a los Ayuntamientos, que no podrán actuar con rectitud en situaciones similares.

b) Desde el punto de vista económico, las repercusiones van desde la detracción de espacios productivos, hasta la alteración irracional del mercado de suelo agrícola destinado a una función residencial, además del despilfarro de recursos invertidos en construcciones e infraestructuras a uso parcial.

c) En el aspecto ecológico, la construcción indiscriminada sobre territorios, incluso protegidos, reduce o destruye los espacios naturales, la belleza paisajistica queda afectada y se interrumpen los ritmos de vida, que en ellos se cobijan.

d) La incidencia sobre la estructura agraria, es también notable, porque la parcelación contribuye a fragmentar más la propiedad y como quiera que muchos propietarios-promotores son absentistas, induce a la descapitalización del campo en beneficio de la ciudad.

e) Sobre el medio rural, la aparición de "huertos familiares", con sus casitas, sus pozos y sus costumbres, en general es tambien negativa: destruyen los suelos de huerta, se contaminan las aguas, las haciendas locales no se benefician del régimen impositivo sobre los usos urbanos, ni de las tasas por el otorgamiento de licencias. 
f) Producen, asi mismo, alteraciones en la convivencia vecinal, porque los habitantes del medio rural, sin recibir compensación alguna por la colonización de su territorio, se sienten víctimas del poco respeto hacia el campo y sus costumbres por parte de los nuevos vecinos: cortan el agua de las acequias, taponan brazales, congestionan el tráfico en los caminos agrícolas, se producen algunas rapiñas en los frutales y hortalizas, obstruyen los viales, al construir en los mismos linderos...

Otras consecuencias, como el incremento del tráfico rodado, por la concentración en el tiempo, sobre todo a la hora del retorno (7.230 vehículos a razón de 1'5 vehículos por construcción), o las distorsiones en los precios del suelo, canalizando el ahorro de las clases menos favorecidas económicamente hacia un negocio improductivo, son también dignas de consideración.

Distribución espacial . Como se observa en el cuadro y el gráfico correspondiente, las áreas más castigadas por la parcelación clandestina, se extienden por todos los ejes de expansión, apoyadas en la infraestructura de comunicaciones (carreteras y red de caminos), aguas derivadas (acequias y brazales) y el acuífero.

En cuanto a la distancia, hay algunos núcleos muy próximos a là ciudad (El Alfaz o Almozara), pero las mayores concentraciones se hallan en una banda entre los $12-15 \mathrm{~km}$. aunque con el tiempo se ha producido un progresivo alejamiento $(25-30 \mathrm{~km}$.), compensado por la reducción en los precios de las parcelas, que permiten su adquisición a usuarios de menor poder adquisitivo.

Así surgen las promociones de Osera y sobre todo los conjuntos de montepinar, Valdepinar, Bosque Alto o Pinares de La Muela, aprovechando la vegetación arbustiva y bosque claro de pino relicto, la altura de las muelas, que proporciona panorámicas y un paisaje de indudable belleza.

En cualquier caso y siguiendo la tónica de estas promociones, la puesta en valor del suelo se aleja de los cánones tradicionales (planeamiento, dotaciones, accesos, etc.) ofertándose a cambio, paisajes, sol, agua, pureza ambiental y sobre todo, "mucha naturaleza", transformando ese bien de uso, de carácter no consumible, en un bien de cambio, facilmente comercializable y sin inversiones iniciales de cierta magnitud.

\section{PARCELACIONES CLANDESTINAS}

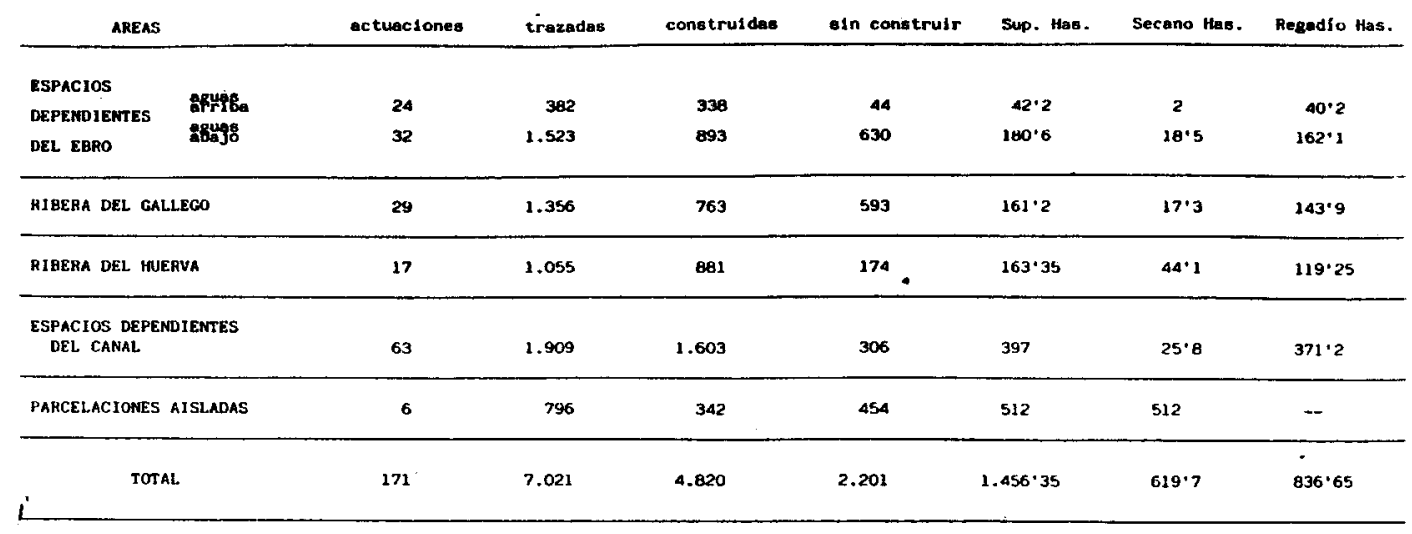




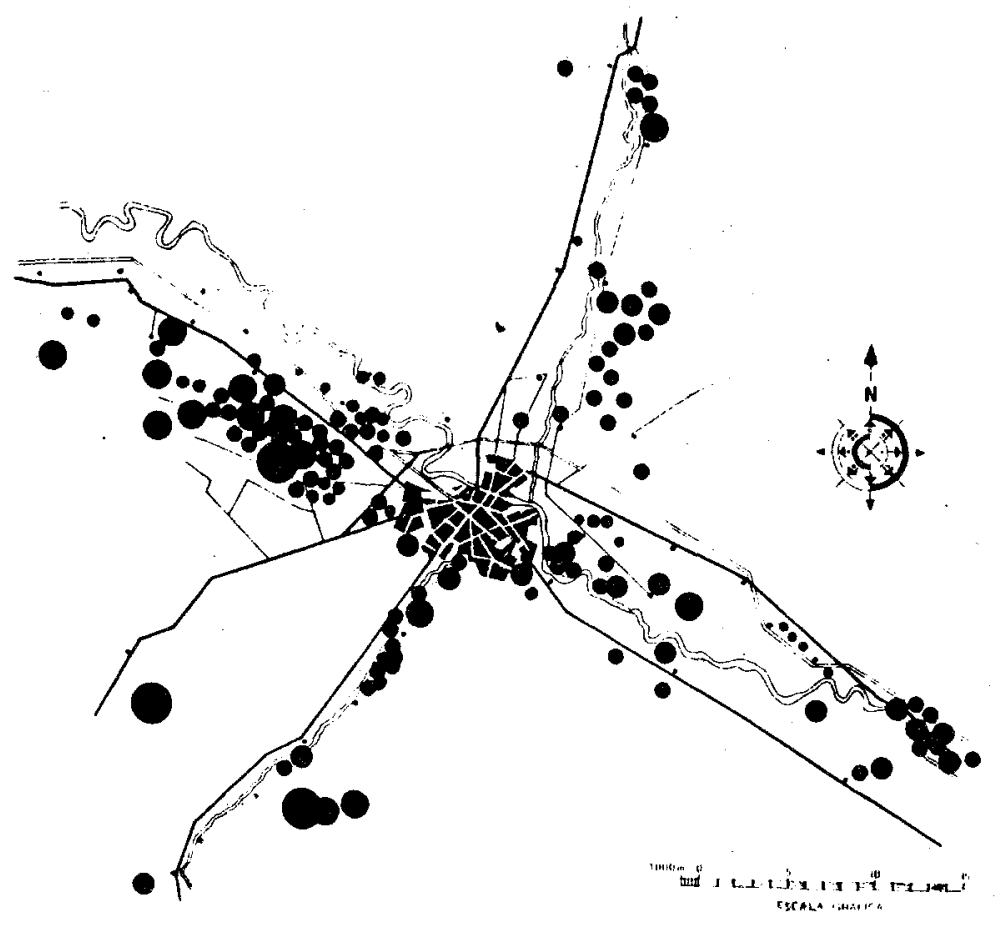

POSIBLES SOLUCIONES. La formación de estos núcleos residenciales en los alrededores de Zaragoza, a una distancia tolerable en el sistema espacio tiempo, representa una amenaza de ruptura y destrucción del ambiente natural y una usurpación de espacios que podrían destinarse a otros usos.

Por otra parte, su aparición al margen de cualquier planeamiento, impide las dotaciones de servicios y el mantenimiento de estándares mínimos de urbanización, imprescindibles en la época en que vivimos. Pero el problema está ahí y a su solución deben ir encaminados los mejores esfuerzos, si bien, a la hora de buscar soluciones, no pueden olvidarse ni las causas que han motivado las parcelaciones, ni otras consideraciones de orden social, que por su propia naturaleza, justifican la promoción. Se debe huir en todo momento de posturas radicales o soluciones globales, porque la problemática es muy variada y exige un tratamiento individualizado, de acuerdo con los rasgos diferenciales de cada promoción y de cada parcela en particular.

Las posibles medidas pueden concretarse en estos grupos:

a) Soluciones precautorias o disuasorias : político de información masiva, para concienciar al ciudadano. Dar solución a la lentitud y altos costes de la legalidad. Intensificar las medidas inspectoras. Delimitar con claridad el sujeto de las sanciones.

b) Soluciones operativas. Antes de su aplicación, conviene matizar y seleccionar las parcelaciones según sus propias peculiaridades: 
1.- En parcelaciones que se asienten sobre terrenos con un gran valor ambiental o paisajístico, lo ideal es restablecer el equilibrio anterior y restaurar el estado primitivo.

2.- Si se sitúan en áreas especialmente aptas para la productividad agraria, las medidas han de ir encaminadas a paralizar el proceso y permitir sólo la construcción de minúsculos refugios agrícolas.

3.- Si se ubican en lugares de alto riesgo, lo más operativo es su desmantelamiento.

4.- Cuando se trate de parcelaciones no comprendidas en los casos anteriores, lo mejor es su legalización, a través del planeamiento, clasificando el suelo como "urbano" o "urbanizable": "programado" o "sin programas", según los casos, y con los sistemas de ejecución que establece la Ley del Suelo: compensación, cooperación o expropiación, tras una serena reflexión y con criterios de racionalidad.

c) Soluciones alternativas. Son muy variadas y, aunque poco espectaculares a corto plazo, si pueden resultar efectivas a medio y largo plazo. Entre ellas cabe citar: mejora de la calidad ambiental de las ciudades. Promoción pública de huertos colectivos. Fomentar la agricultura como posibilidad recreativa. Integrar el "huerto" en el complejo sistema verde periurbano y como una posibilidad de suelo urbanizable.

En definitiva, se trata de dar salida a una situación realmente complicada, en la que hay algo más que pura maniobra especulativa y para la que la normativa rígida, o las medidas sancionadoras no pueden ser las únicas que permitan el disfrute de la naturaleza sin el riesgo de ilegalidad.

En esta tarea deben intervenir coordinada, responsable y desciplinariamente las distintas administraciones:

La Central, a través de las Direcciones Provinciales de los ministerios afectados.

La Autonómica, a través de la Comisión Provincial de Urbanismo.

La Local, a través de las Diputaciones Provinciales (art. 217 de la L.S.) y Ayuntamientos (Art. 214 de la L.S.).

La Corporativa, a través de los Colegios de Arquitectos, Notarial y Registradores de la Propiedad.

Por lo expuesto, concluir que la labor de los Ayuntamientos debe ir encaminada a ofrecer alternativas claras al establecimiento de este tipo de promociones, que como puede comprobarse, obedecen a una demanda y hasta a una necesidad social.

En definitiva, no se trata de prohibir solamente, sino de comprender el problema y con verdadera voluntad, tratar de resolverlo. 